\section{Activation of Staphylococcal-free Coagulase by Purified Human Prothrombin}

Free coagulase ${ }^{1}$ is an extracellular protein produced by pathogenic staphylococci ${ }^{2}$, which reacts with coagulase activator ${ }^{3}$, present in the plasma of certain animal species, to yield an active material capable of clotting any fibrinogen ${ }^{1}$. The active material has been called activated coagulase ${ }^{4}$ and has been shown recently, by a study of the kinetics of the reaction between purified free coagulase ${ }^{5}$ and an impure preparation of coagulase activator, to be produced during the enzymic degradation of the former by the latter. This work, however, shed no light on the vexed problem of the nature of coagulase activator ${ }^{3,6-9}$, owing to the inhomogeneity of the coagulase activator preparation employed.

Through the kindness of Dr. F. Duckert of the Medizinische Universitätsklinik, Zurich, we have been able to repeat some of these experiments, using, as the source of coagulase activator, a highly purified sample of human prothrombin prepared by chromatography on barium sulphate and 'Hyflosupercel' by a slight modification of the method used by Duckert, Koller and Matter ${ }^{10}$. This material contained about 1,000 units of prothrombin and 160 units of coagulase activator per mgma. protein, and was thus enriched between 600 and 700 times (Dr. Duckert, private communication).

Solutions of prothrombin in phosphate buffer (0.07 $M$ disodium hydrogen phosphate-potassium dihydrogen phosphate, $p \mathrm{H}$ 6.8) were incubated at $37^{\circ} \mathrm{C}$. with various concentrations of free coagulase and activated coagulase was assayed in the mixtures as already described ${ }^{4}$. The results, which are summarized in Table 1, are essentially similar to those obtained previously ${ }^{4}$ and demonstrate the instability of activated coagulase under these conditions. The concentration of activated coagulase produced and the length of time before its exhaustion are directly dependent upon the initial concentration of free coagulase in the mixture. These facts, together with the finding that the exhausted mixtures still contain coagulase activator but no free coagulase, confirm that free coagulase is enzymically degraded by coagulase activator.

Table 1. Formation and Destruction of ACtivated CoAgulase in Mixtures containing a Constant amount of Purified Human PROTHROMBIN AND VARIOUS AMOUNTS OF FREE COAGULASE Values given are for the concentration of activated coagulase (units/ml.)

\begin{tabular}{|c|c|c|c|c|}
\hline \multirow{2}{*}{$\begin{array}{l}\text { Incubation } \\
\text { time of } \\
\text { mixture at } \\
37^{\circ} \mathrm{C} \text {. (hr.) }\end{array}$} & \multicolumn{4}{|c|}{$\begin{array}{l}\text { Concentration of coagulase (units } / \mathrm{ml} \text {.) added to } \\
\text { an equal volume of purifled human prothrombin } \\
(250 \mathrm{gmm} . / \mathrm{ml} .)\end{array}$} \\
\hline & 25 & 10 & 5 & 2 \\
\hline $\begin{array}{r}0 \\
1 \\
2 \\
3 \\
4 \\
5 \\
6 \\
8 \\
22\end{array}$ & $\begin{array}{l}3 \cdot 3 \\
4 \cdot 3 \\
4 \cdot 0 \\
4 \cdot 0 \\
3 \cdot 8 \\
4 \cdot 3 \\
4 \cdot 0 \\
3 \cdot 0 \\
1 \cdot 5\end{array}$ & $\begin{array}{l}1.9 \\
2.8 \\
2 \cdot 8 \\
2 \cdot 4 \\
2 \cdot 4 \\
1 \cdot 5 \\
1 \cdot 4 \\
0.8 \\
0.9\end{array}$ & $\begin{array}{l}1 \cdot 2 \\
1 \cdot 4 \\
1 \cdot 4 \\
1 \cdot 4 \\
0 \cdot 9 \\
0.8 \\
0 \cdot 6 \\
0.5 \\
0.34\end{array}$ & $\begin{array}{l}0.5 \\
0.6 \\
0.6 \\
0.5 \\
0.3 \\
0.25 \\
0.23 \\
0.17 \\
0.08\end{array}$ \\
\hline
\end{tabular}

After incubation for $22 \mathrm{hr}$. the mixtures were divided into three portions and to $(a)$ was added an equal volume of prothrombin $190 \mu \mathrm{gm}$. $/ \mathrm{ml}$., to $(b)$ an equal volume of coagulase $25 \mathrm{units} / \mathrm{ml}$, and to (c) an equal volume of buffer. They were then incubated for $10 \mathrm{~min}$. and the activated coagulase content measured as before.

\begin{tabular}{|l|l|l|l|l|}
$a$ & 0.5 & 0.12 & $<0.1$ & $<0.1$ \\
$b$ & 3.1 & 2.7 & 2.0 & 2.0 \\
$c$ & 0.5 & 0.13 & $<0.1$ & $<0.1$ \\
\hline
\end{tabular}

In view of the highly purified nature of the human prothrombin used as a source of coagulase activator, it seems likely that the two are identical. This suggestion is supported by the observation that the ratio of prothrombin to coagulase activator in normal human plasma is identical with that in the present highly purified preparation of prothrombin.

G. HaUghton*

E. S. Duthie

Royal South Hants Hospital,

Southampton. March 26.

* Present address : Microbiologieal Research Establishment, Porton, Nr. Salisbury.

${ }^{1}$ Duthie, E. S., J. Gen. Mierobiol., 10, 427 (1951).

${ }^{2}$ Much, H., Biochem. Z., 14, 143 (1908).

${ }^{3}$ Smith, W., and Hale, J. H., Brit. J. Exp. Path., 25, 101 (1944).

${ }^{4}$ Haughton, G., and Duthie, E. S., Biochem. J., 71, 348 (1959).

${ }^{5}$ Duthie, E. S., and Haughton, G., Biochem. J., 70, 125 (1958).

- Duthie, E. S., and Lorenz, L. L., J. Gen. Microbiol., 6, 95 (1952)

? Tager, M., Yale J. Biol. Med., 20, 369 (1948).

${ }^{8}$ Tager, M., J. Exp. Med., 104, 675 (1956).

- Haughton, G., Ph.D. thesis, University of Southampton (1958).

${ }^{10}$ Duckert, F., Koller, F., and Matter, M., Proc. Soc. Exp. Biol. Med. 82, 259 (i953).

\section{CHEMISTRY}

\section{Separation of Polyvinyl Chloride and Polyvinyl Acetate by Chromatographic Methods}

The material used in this work was known to contain at least two co-polymers. A method of separation was sought which would not require a complex chemical procedure. The separation of high polymers by chromatographic means was carried out by Claesson ${ }^{1}$, while separations on columns packed with carbon black were attempted by Landler ${ }^{2}$.

It was found that absorption decreased with increased molecular weight. A column of activated charcoal was packed and saturated with methyl iso-butyl ketone. The mixture containing the two co-polymers in this solvent was added to the top of the column and washed with the solvent. After a few minutes, the elutant was giving a positive test for chloride. After $1 \mathrm{hr}$. washing the fractions began to give positive acetate results.

In order to attempt some form of confirmation, a method of separation was devised by paper chromatography.

The mixed co-polymers in solution were spotted on to a strip of Whatman's No. 4 filter paper and airdried. This strip was then allowed to run at room temperature for $45 \mathrm{~min}$., using once again methyl iso-butyl ketone as a solvent. The strip was then air-dried and sprayed with a solution of one part B.D.H. Universal indicator and one part distilled water. The whole strip was then washed in distilled water and dried. The acetate spot remained stationary, while the chloride moved with the solvent front. $R_{F}$ values were for chloride 0.985 and 0.0 for the acetate. Both spots were eluted, yielding positive tests for acetate and chloride, respectively.

To determine the accuracy of the separation, two pure polymers of acetate and chloride were mixed in the solvent. These were then spotted on to a No. 4 filter paper and run as a control. Identical results were obtained as with the mixed co-polymers.

This method is not suggested as an analytical procedure but as a rapid means of separating mixed polymers. 